\title{
A DINÂMICA ATMOSFÉRICA NO CENTRO-SUL DO BRASIL NO VERÃO E AS INFLUENCIAS DO EL NIÑO OSCILAÇÃO SUL (ENOS)
}

\author{
Victor da Assunção Borsato ${ }^{1}$
}

\begin{abstract}
Resumo: Estudou-se a dinâmica atmosférica do Centro-Sul do Brasil a partir de quatro estações climatológicas, situadas nas regiões de Campo Mourão - PR, Cáceres - MT, Brasília DF e Caparaó - MG, em três verões. O verão se destaca pelas abundantes chuvas convectivas, principalmente ao norte da linha do trópico de Capricórnio. No Sul do Brasil a variabilidade interanual se amplia em anos de El Niño e de La Niña, e sobre a região situada ao norte do trópico não há informações precisas. Para investigar a dinâmica das massas de ar que atuaram no Centro-Sul do Brasil e a gênese das chuvas foram estudados os sistemas atmosféricos por meio da espacialização temporal. O objetivo principal foi verificar a porcentagem das chuvas frontais e convectivas e contabilizar a participação das massas de ar na dinâmica atmosférica na estação do verão em um ano climatológico normal (2008/2009), em um de manifestação da La Niña (2007/2008) e em um de El Niño (2009/2010). Em Cáceres e Brasília o tempo de atuação da massa Polar atlântica se limita a eventos esporádicos, enquanto a massa Equatorial continental aumenta na mesma proporção, tendo como a principal consequência as chuvas convectivas. Constatou-se também que em Campo Mourão e Caparaó os sistemas frontais, as massas Polar atlântica e Tropical atlântica participaram ativamente nos tipos de tempo. Embora pesquisas neste sentido ainda sejam escassas, constatou-se neste estudo que no verão de 2007/2008, de manifestação da La Niña, o volume de chuva foi maior e a participação dos sistemas atmosféricos também.
\end{abstract}

Palavras chave: climatologia; sistemas atmosféricos; pluviosidade.

\section{THE ATMOSPHERIC DYNAMICS IN THE SOUTH CENTRAL BRAZIL IN THE SUMMER AND THE INFLUENCE OF THE EL NINO SOUTHERN OSCILLATION (ENSO)}

\begin{abstract}
The atmospheric dynamics of the Central Southern Brazil was studied by means of four weather stations situated in the area of Campo Mourao, PR, Caceres, MT, Brasilia, DF and Caparao MG in three summers. The summer is characterized by abundant convective rains, mainly in the north of the Tropic of Capricorn. In southern Brazil the interannual variability is increased in years of El Nino and La Nina, and on the region lying north of the tropics there is no accurate information. To investigate the dynamics of air masses that were active in the South-Center of Brazil and the genesis of the rain, weather systems were studied by means of the spatial- temporal patterns. The main aim was to determine the percentage of frontal and convective rainfall and account for the involvement of the air masses in the atmospheric dynamics in the summer, in a climatologic normal year (2008/2009), in a year with the manifestation of the La Nina (2007/2008) and in a year with El Nino (2009/2010). In Caceres and in Brasilia the time of action of the Polar Atlantic mass is limited to sporadic
\end{abstract}

${ }^{1}$ Professor Adjunto do Departamento de Geografia da FECILCAM - E-mail: victorb@fecilcam.br DOI: 10.7154/RDG.2011.0022.0007 
events, while the continental Equatorial mass increases at the same rate. The main consequence of this is the convective rainfall. It was also found that for Campo Mourao and Caparao the frontal systems, the Polar Atlantic and the Atlantic Tropical masses contributed actively to the types of weather. Although there are few researches regarding this theme, in this study it was found that in the summer of 2007/2008, of La Nina event, the rainfall was higher.

Keywords: Climatology; Weather systems; rainfall.

\section{INTRODUÇÃO}

Todos os eventos do fenômeno El Niño Oscilação Sul (ENOS) causam preocupações aos meteorologistas e climatologistas. O fenômeno provoca anomalias no clima global e no regional. A cada nova ocorrência do fenômeno há um crescimento no interesse e, consequentemente, o surgimento de novas pesquisas a seu respeito.

O Sul do Brasil é uma das regiões onde as pesquisas mostram que o El Niño causa impacto, principalmente no tocante às chuvas. Nos trabalhos de Kousky et al. (1984), Rao e Hada (1990), Ropelevski e Halpert (1987) e Grimm e Gomes (1996) foram estudadas as consequências do fenômeno principalmente sobre a distribuição e altura das precipitações nas diferentes regiões do globo e do Brasil.

O Centro-Sul do Brasil é uma grande região e abrange dez estados da Federação. Nela os climas predominantes são o tropical típico ao norte da linha do trópico de Capricórnio e o temperado ao sul. O trópico delimita uma ampla faixa de transição entre o clima tropical e o temperado.

A grande extensão da região justifica uma diversidade de formas de relevo que se estende do litoral ao centro do continente sul-americano; por isso têm-se subtipos climáticos influenciados pela maritimidade, pelo relevo, pela continentalidade e, na escala sinótica, pela dinâmica atmosférica, comandados pela circulação geral e pelas massas de ar.

A dinâmica das massas de ar que atuam no Sul e Sudeste do Brasil já foi caracterizada a partir dos estudos de Monteiro (1969), embora trabalhos sobre a pluviosidade precedam o desse autor. Schroder (1956) analisou a distribuição das chuvas no Estado de São Paulo no período de 1941 a 1951. Monteiro (1976), por meio da análise rítmica, caracterizou as gêneses das chuvas e a dinâmica das massas de ar. Tarifa (1973) também deu a sua contribuição em "Sucessão dos tipos de tempo e a variação do balanço hídrico no extremo Oeste Paulista". Boin (2000) fez estudos sobre as chuvas e a erosão no Oeste Paulista. Borsato (2006) estudou a dinâmica atmosférica na bacia hidrográfica do Alto Rio Paraná. A grande maioria 
dos estudos que abordam a climatologia dinâmica adotou o ano padrão, as excepcionalidades ou, ainda, um curto período do ano ou uma estação. Para Zavattini (2003), resta delimitar mais precisamente até onde, dentro do país, tais características do ritmo climático se manifestam, ou seja, delimitar as áreas por meio das afinidades rítmicas regionais e sub-regionais.

O principal objetivo foi contabilizar a participação das massas de ar na dinâmica atmosférica na estação do verão em três anos consecutivos, dos quais o primeiro foi caracterizado pela manifestação da La Niña (2007/2008), o segundo foi climatologicamente normal (2008/2009) e o terceiro foi marcado pelo El Niño (2009/2010). Outro objetivo foi verificar a espacialização e altura das chuvas frontais e convectivas nesses três verãos e verificar se o El Niño e a La Niña causam impacto na mesma.

A escolha da estação do verão justifica-se por ser esta estação a mais úmida por nela predominarem os sistemas de baixa pressão. Os resultados serão apresentados em tabelas e gráficos, os quais poderão ser comparados entre si. Também se estudou a gênese das chuvas por meio do sistema atmosférico atuante.

No estudo do clima, principalmente quando se pretende caracterizá-lo, é fundamental considerar os fatores geográficos locais, por meio da variação da altitude, da forma e orientação das vertentes, relacionado-as com a direção predominante dos ventos. 0 presente estudo da dinâmica atmosférica foi de escala regional e feito por meio das participações dos sistemas atmosférico, não sendo possível considerar os fatores locais. Para considerá-los seriam necessários mais tempo e recursos para visitar as estações climatológicas e fazer uma análise geográfica particularizada na região e no entorno de cada estação.

O presente estudo focalizou principalmente o interior dessa grande região, priorizando quatro estações climatológicas principais: a de Campo Mourão, no Paraná, a de Cáceres, no Mato Grosso, a de Brasília, Distrito Federal, e a de Caparaó, em Minas Gerais. O estudo da dinâmica atmosférica a partir dessas localidades forneceu informações suficientes para a caracterização da dinâmica atmosférica nos verões de 2007/2008, 2008/2009 e 2009/2010. A contabilização da participação dos sistemas atmosféricos nas quatro localidades dessa grande região geográfica mostra quanto o El Niño e a La Niña influenciam a dinâmica dos sistemas atmosféricos, refletidos no tempo cronológico de participação dos sistemas atmosféricos e na gênese das chuvas, que são classificadas como frontais ou convectivas. 


\section{O El Niño - Oscilação Sul}

O El Niño é caracterizado por temperaturas anormalmente quentes do oceano no Pacífico Equatorial, ao contrário de La Niña, que se caracteriza por temperaturas anormalmente frias. O El Niño é uma oscilação do sistema oceano-atmosfera no Pacífico Tropical e provoca consequências importantes no tempo atmosférico em todo o globo (NOAA 2011).

Admite-se que existem cerca de vinte regiões do mundo cujo clima é afetado pelas fases do El Niño e La Niña Oscilação Sul (ENOS). No Brasil, o setor norte da Região Nordeste, a parte leste da Região Amazônica (na faixa tropical) e a Região Sul do Brasil são as mais afetadas por essa anomalia (CUNHA, 1999).

O ENOS resulta da interação entre o oceano e a atmosfera, a qual provoca anomalias nos padrões climáticos, com fortes mudanças nas condições do tempo em várias partes do mundo (CLIMANÁLISE, 2000). O ENOS é um fenômeno de grande escala, cujas regiões de origem estão situadas no Pacífico Tropical (BERLATO; FONTANA, 2000).

O fenômeno é caracterizado por dois componentes; um de natureza oceânica (El Niño), associado às mudanças na temperatura da água, e o outro de natureza atmosférica (Oscilação Sul), relacionado à correlação inversa existente entre a pressão atmosférica no extremo leste e oeste do Pacífico Tropical (BERLATO; FONTANA, 2000).

Segundo o Instituto National Oceanic and Atmospheric Administration (NOAA, 2000; CAPEL MOLINA, 1999), em períodos de condições normais os ventos alísios sopram para o oeste no Pacífico Tropical, arrastando as águas superficiais mais aquecidas para a porção ocidental desse oceano, e esse movimento continuamente promove o soerguimento no nível das águas na porção ocidental e rebaixamento na porção oriental do Pacífico, acumulando uma massa de água superaquecida de considerável volume. Esse movimento, além de provocar a ressurgência de águas frias no Pacífico Tropical Oriental, causa um desequilíbrio na pressão atmosférica, ou seja, pressão mais alta no setor oriental e mais baixa no setor ocidental.

Durante a fase negativa o mecanismo se inverte, os ventos alísios se debilitam e às vezes chegam a inverter-se, e como as águas aquecidas são trazidas para a costa, a ressurgência é inibida e favorece o aquecimento superficial nas proximidades da costa sul-americana. A convecção instala-se em função do aquecimento, mudando a configuração da célula de Walker, e o ar ora ascende nessa porção, ora desce sobre o território brasileiro, nas regiões onde na fase positiva ascendia. Esse mecanismo promove a escassez de chuva nas regiões 
citadas (NOAA, 2000; INFOCLIMA, 1999). Outro extremo da variação é representado pelas condições da La Niña, quando ocorre um resfriamento das águas e o consequente aumento da pressão atmosférica na porção leste do Pacífico, fenômeno a que se chama também de fase fria ou fase positiva.

A célula de Walker se configura pelos ventos que ascendem na costa da Austrália, região de águas aquecidas, e fluem em direção leste e fecham a célula com a descência do ar seco sobre o Pacífico Oriental (seco porque, ao subir, perde umidade e causa intensas precipitações) (NERY et al. 1998).

O El Niño foi originalmente reconhecido por pescadores na costa da América do Sul com o aparecimento de água anormalmente mais quente no Oceano Pacífico, chegando ao grau máximo no final do ano, quando se comemora o Natal, ou seja, o nascimento do Menino Jesus. El Niño significa "o menino" em espanhol. A tabela 01 mostra os anos de evidência do fenômeno a partir de 1997.

Tabela 01 - Anos de ocorrência dos fenômenos El Niño e La Niña no período de 1997 a 2010.

\begin{tabular}{cc}
\hline El Niño & La Niña \\
\hline anos & anos \\
$1997-1998$ & $1998-1999$ \\
$2002-2003$ & $2000-2001$ \\
$2004-2005$ & 2006 (início) \\
$2006-2007$ & $2007-2008$ \\
2009 & 2010 (final) \\
\hline
\end{tabular}

Fonte - NOAA, 2011.

Quadro 01 - Oscilação da temperatura a partir da média mensal no Oceano Pacífico em 5으 N e 5오 e 120ㅇ e 170W no período de 2000 a maio de 2011

\begin{tabular}{|c|c|c|c|c|c|c|c|c|c|c|c|c|}
\hline ano & jan. & fev. & mar. & abr. & maio & jun. & jul. & agos. & set. & out. & nov. & dez. \\
\hline 2000 & $-1,6$ & $-1,4$ & -1 & $-0,8$ & $-0,6$ & $-0,5$ & $-0,4$ & $-0,4$ & $-0,4$ & $-0,5$ & $-0,6$ & $-0,7$ \\
\hline 2001 & $-0,6$ & $-0,5$ & $-0,4$ & $-0,2$ & $-0,1$ & 0,1 & 0,2 & 0,2 & 0,1 & 0 & $-0,1$ & $-0,1$ \\
\hline 2002 & $-0,1$ & 0,1 & 0,2 & 0,4 & 0,7 & 0,8 & 0,9 & 1 & 1,1 & 1,3 & 1,5 & 1,4 \\
\hline 2003 & 1,2 & 0,9 & 0,5 & 0,1 & $-0,1$ & 0,1 & 0,4 & 0,5 & 0,6 & 0,5 & 0,6 & 0,4 \\
\hline 2004 & 0,4 & 0,3 & 0,2 & 0,2 & 0,3 & 0,5 & 0,7 & 0,8 & 0,9 & 0,8 & 0,8 & 0,8 \\
\hline 2005 & 0,7 & 0,5 & 0,4 & 0,4 & 0,4 & 0,4 & 0,4 & 0,3 & 0,2 & $-0,1$ & $-0,4$ & $-0,7$ \\
\hline 2006 & $-0,7$ & $-0,6$ & $-0,4$ & $-0,1$ & 0,1 & 0,2 & 0,3 & 0,5 & 0,6 & 0,9 & 1,1 & 1,1 \\
\hline 2007 & 0,8 & 0,4 & 0,1 & $-0,1$ & $-0,1$ & $-0,1$ & $-0,1$ & $-0,4$ & $-0,7$ & -1 & $-1,1$ & $-1,3$ \\
\hline 2008 & $-1,4$ & $-1,4$ & $-1,1$ & $-0,8$ & $-0,6$ & $-0,4$ & $-0,1$ & 0 & 0 & 0 & $-0,3$ & $-0,6$ \\
\hline 2009 & $-0,8$ & $-0,7$ & $-0,5$ & $-0,1$ & 0,2 & 0,6 & 0,7 & 0,8 & 0,9 & 1,2 & 1,5 & 1,8 \\
\hline 2010 & 1,7 & 1,5 & 1,2 & 0,8 & 0,3 & $-0,2$ & $-0,6$ & -1 & $-1,3$ & $-1,4$ & $-1,4$ & $-1,4$ \\
\hline 2011 & $-1,3$ & $-1,2$ & $-0,9$ & $-0,6$ & $-0,2$ & II & /I & /I & $/ /$ & $/ /$ & // & /I \\
\hline
\end{tabular}

Fonte: NOAA, 2011. 
O Instituto NOAA monitora a temperatura da água da superfície do Pacífico Equatorial, e todas as vezes que esta exceder a média em 0,5 으 por um período superior a três meses se evidencia o fenômeno. 0 quadro 01 mostra a temperatura média monitorada na década de 2000 - em vermelho, El Niño, e em azul, La Niña.

\section{METODOLOGIA}

Com o propósito de estudar a dinâmica das massas de ar no Centro-Sul do Brasil, procedeuse à escolha das estações climatológicas de Campo Mourão - PR, Cáceres - MS, Brasília - DF e Caparaó - MG (figura 01). Na sequência foram organizadas em tabelas do Excel colunas para os sistemas atmosféricos, para pressão e para as chuvas frontais e convectivas. Os dados dos elementos do tempo foram fornecidos pelo Instituto Nacional de Meteorologia do Governo Federal (INMET).

Os sistemas atmosféricos considerados foram aqueles que atuaram no Centro-Sul do Brasil nos três verões, ou seja, o Sistema Frontal (SF), a massa Tropical continental (mTc), a massa Tropical atlântica (mTa), a massa Polar atlântica (mPa) e a massa Equatorial continental (mEc) (FERREIRA 1989; VAREJÃO-SILVA 2000; VIANELLO 2000; BISCARO 2007).

Para o registro dos sistemas identificados nas cartas sinóticas da Marinha do Brasil (MAR.MIL 2010), nas imagens de satélite no canal infravermelho (CPTEC.INPE.BR 2010) e nos elementos do tempo, foram organizadas tabelas em planilha do Excel com os dias de todo o período e colunas para os sistemas atmosféricos atuantes, para a pressão atmosférica e para as chuvas, as quais foram classificadas como frontais ou convectivas, a depender do sistema atmosférico. Para o dia em que um único sistema atuou atribui-se o número 24 na coluna correspondente ao sistema, número que corresponde às horas do dia, e 12 para cada sistema nos dias em que a localidade se encontrava na confluência entre dois sistemas. No final da estação foram somados os valores de cada coluna e calculadas as porcentagens.

Para definir o sistema atuante, além das análises e da localização dos centros ciclonais e anticiclonais, fez-se a leitura da pressão na carta sinótica da Marinha do Brasil das 12H TMG e analisou-se a cobertura do céu por meio das imagens de satélite no canal infravermelho das 12H TMG (CPTEC-INPE). Foram verificadas a direção dos ventos no mesmo horário e a temperatura, também das $12 \mathrm{H}$ TMG, além das temperaturas máxima e mínima do dia. 
Para a classificação da gênese das chuvas considerou-se frontal o volume registrado nos dias em que se verificou que a localidade se encontrava sob o SF ou mPa e convectiva para os demais sistemas atmosféricos.

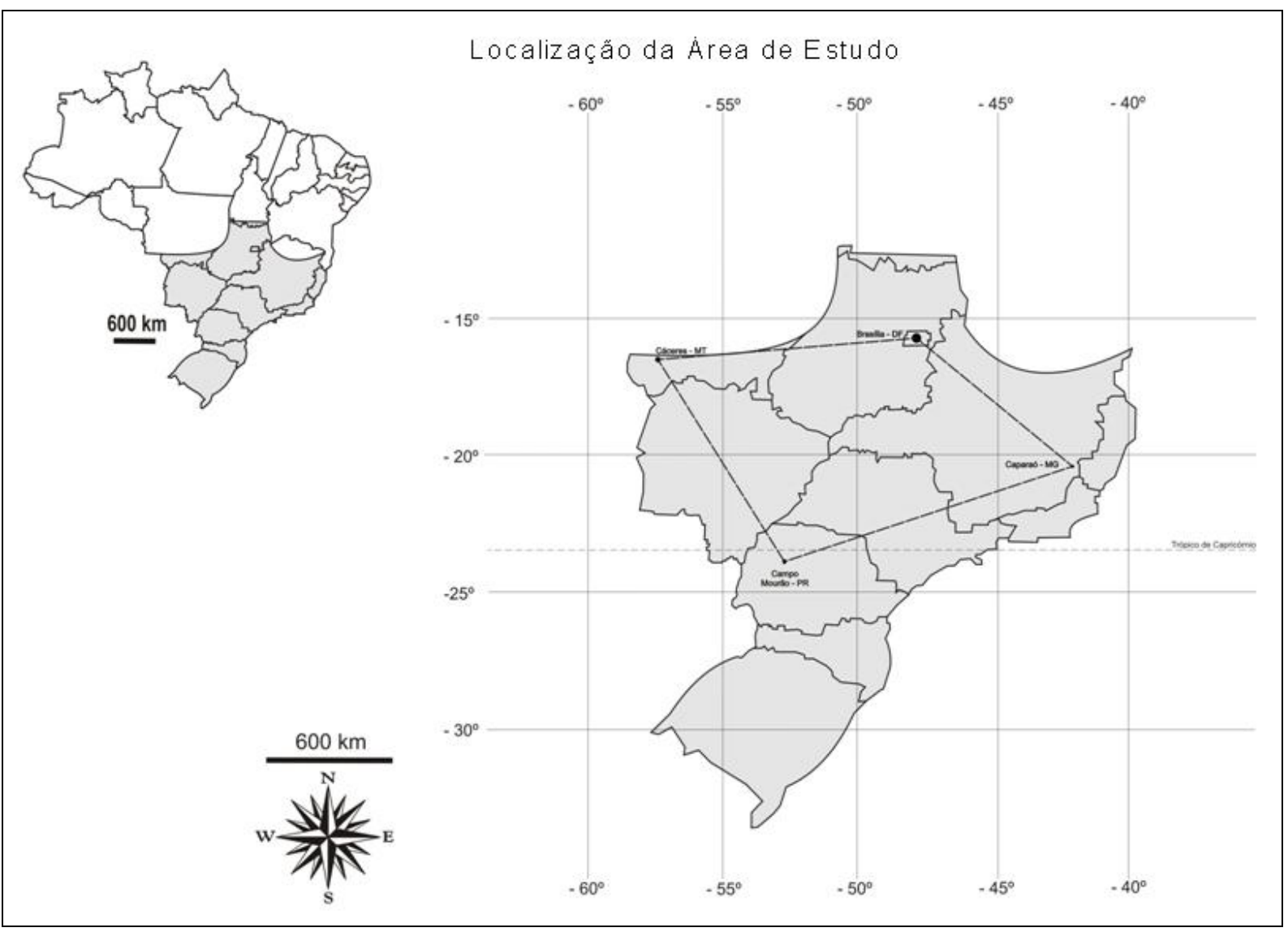

Figura 1: Localização da região de estudo, Macro região Centro Sul do Brasil. Organização do autor

\section{ANÁLISES DOS RESULTADOS}

As massas de ar se originam em grandes áreas homogêneas da Terra e apresentam como características a homogeneidade da pressão, a umidade e temperatura e seus movimentos. Na dinâmica, sucessivamente, enquanto uma avança a outra recua. Neste sentido, o tipo de tempo é consequência das características da massa de ar que esteja atuando naquela região e da interação que se dá entre os elementos do tempo e as formas de relevo, ou seja, da sua altitude, das características da cobertura vegetal e da orientação das vertentes. Um sistema anticiclonal, ao avançar sobre uma região tropical continental, impõe suas características, 
causando mudanças no tempo, e depois de dois ou mais dias as suas características originais vão se modificando.

Por questões relacionadas à circulação geral da atmosfera, as massas de ar frequentemente abandonam a região de origem, conduzindo consigo as propriedades lá adquiridas. No trajeto, podem causar profundas alterações nas condições prevalecentes do tempo, das áreas aonde chegam, à medida que também vão se modificando em suas características originais (VAREJÃO - SILVA, 2000 371p.)

O Centro-Sul está situado numa zona climática em que a dinâmica das massas de ar sofre alternâncias constantes entre os sistemas de baixa e de alta pressão. No verão a incidência mais perpendicular dos raios solares proporciona maior atividade dos sistemas tropicais continentais, em virtude do maior aquecimento do continente em relação ao mar; a depressão térmica continental (baixa do Chaco) e a depressão do Alto Amazonas acham-se aprofundados, enquanto o anticiclone de origem polar encontra-se enfraquecido (NIMER 1989).

Todas as massas de ar que no verão atuaram ao norte do trópico de Capricórnio, na região Centro-Sul do Brasil, foram analisadas com relação à duração, à área de atuação, à trajetória e à importância no estado do tempo. Essas análises mostraram que a região está sujeita à atuação da $\mathrm{mPa}$, da $\mathrm{mTa}$, da $\mathrm{mTc}$, da $\mathrm{mEc}$ e também dos SFs e da Zona de Convergência do Atlântico Sul (ZCAS). A intensidade não foi objeto de investigação e a duração está condicionada à sua trajetória e sua intensidade. A figura 02 mostra o mapa do Centro Sul do Brasil e a posição aproximada dos Centros ciclonais e anticiclonais que atuam no clima dessa região na estação do verão. Dos sistemas que atuam na região de estudo, a mEc e a mTc se ampliam, principalmente em função do intenso aquecimento continental, enquanto a $\mathrm{mPa}$ e mTa se ampliam, impulsionados pelos ventos divergentes.

O verão se caracteriza como a estação mais úmida e é popularmente denominado de estação das águas. Os sistemas de baixa pressão se expandem a partir do centro de origem e dominam os tipos de tempo em quase toda a região. Em Campo Mourão e Caparaó a mPa atua esporadicamente, e depois que ela deixa o continente e avança para interior do Atlântico é assimilada pela mTa, que freqüentemente atua no leste do Sudeste e do Nordeste do Brasil e raramente chega ao interior do Centro-Sul do Brasil. 


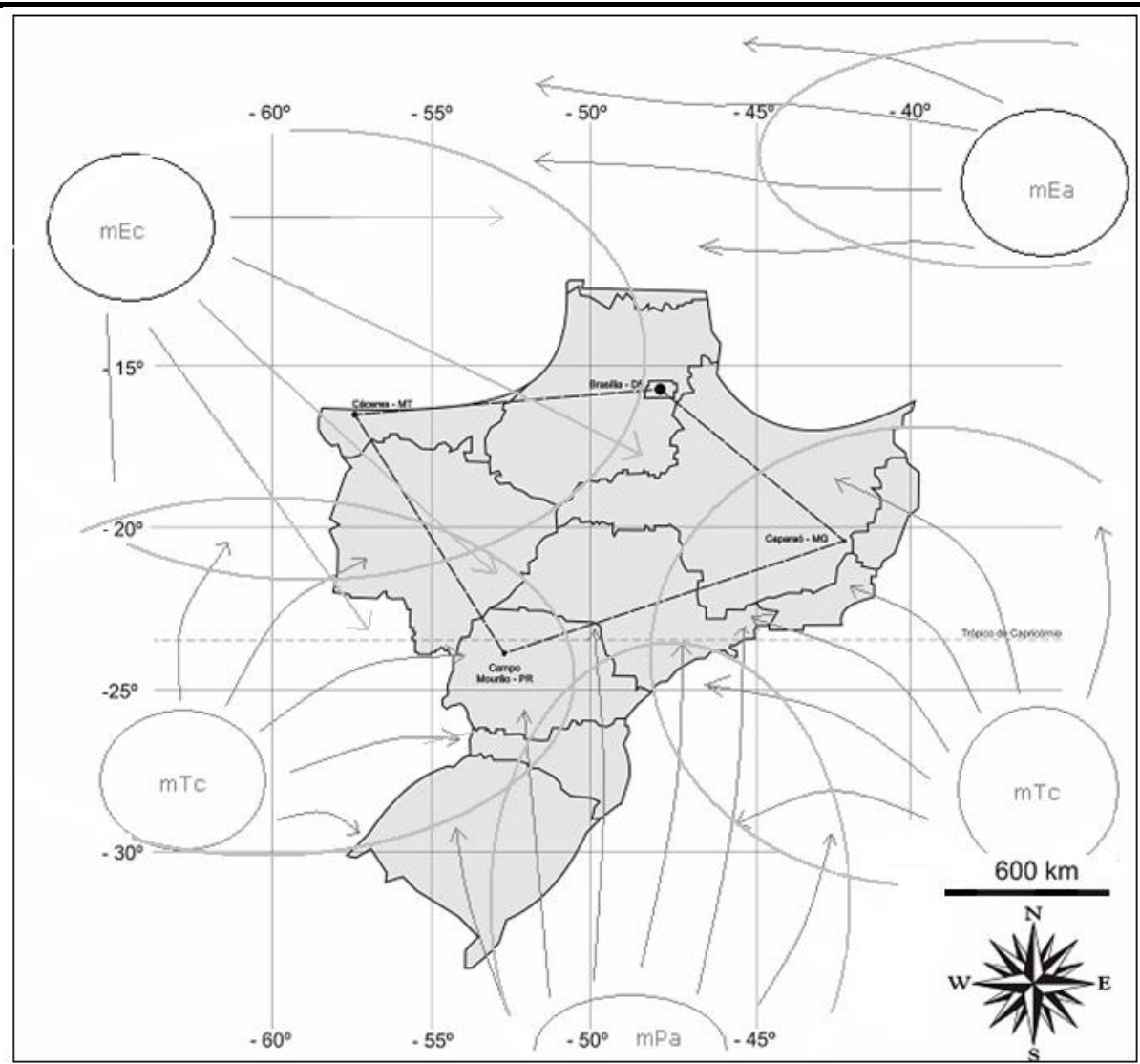

Figura 2: Centro-Sul do Brasil: localização aproximada dos centros de ações das massas de ar que atuam no clima da região Centro Sul do Brasil (organização do autor)

\section{Sistema frontal}

Frente é uma camada ou uma estreita faixa de transição, normalmente com vários quilômetros de espessura, onde se verifica a mistura entre o ar das duas massas presentes, as quais são de características térmicas diferentes. Pela diferença de densidade e direção dos ventos, uma zona de convergência se estabelece nessa faixa, instabilizando a atmosfera. No Centro-Sul do Brasil os sistemas frontais são desencadeados pelo deslocamento da massa Polar atlântica que avança pelo território brasileiro a partir do Sul. Em sua trajetória habitual no verão a mPa avança pelo interior da Região Sul do Brasil, pelo litoral e pelo Atlântico Sul. Na latitude do trópico de Capricórnio, a porção continental já se deslocou para o oceano (Atlântico). Frequentemente, cristas da mPa estendem-se pelo interior do continente e atingem as coordenadas de Campo Mourão e, raramente, as de Cáceres.

As frentes se classificam, de acordo com as características térmicas da massa de ar que as segue, em quentes e frias. Nesse estudo, por uma questão de brevidade, as frentes não foram classificadas e tanto as frias como as quentes, em qualquer dos seus estágios de desenvolvimento, foram denominadas de sistemas frontais. 
Os resultados mostram que o tempo de atuação dos SFs foi maior para o verão de 2007/2008, com 27,7\% em Campo Mourão, 27,2\% em Caparaó, 2,2\% em Cáceres e 8,2\% em Brasília. A tabela 02 mostra a porcentagem da participação dos sistemas frontais nos três verões estudados. Esperava-se que em anos de La Niña o tempo de atuação fosse menor. Para Berlato e Fontana (2003), nos anos de manifestação da La Niña os SFs passam mais rapidamente pelo Sul do Brasil, por isso as precipitações ficam abaixo da média climatológica para Rio Grande do Sul.

Tabela 02 - Porcentagem de participação dos sistemas frontais em Campo Mourão - PR, Cáceres - MT, Caparaó - MG e Brasília - DF nos verões de 2007/2008, 2008/2009 e 2009/2010.

\begin{tabular}{cccc}
\hline Localidades & $2009 / 2010$ & $2008 / 2009$ & $2007 / 2008$ \\
\hline SF & El Niño & Neutro & La Niña \\
Campo Mourão - PR & $15,2 \%$ & $19,1 \%$ & $27,7 \%$ \\
Cáceres - MT & $1,1 \%$ & $1,7 \%$ & $2,2 \%$ \\
Caparaó - MG & $15,4 \%$ & $20,2 \%$ & $27,2 \%$ \\
Brasília - DF & $5,5 \%$ & $2,2 \%$ & $8,2 \%$ \\
\hline
\end{tabular}

A região de Campo Mourão recebeu, no verão 2009/2010, um total de 587,3mm de chuva, dos quais $36,8 \%$ foram de chuvas frontais e $63,2 \%$, de convectivas. No verão $2008 / 2009$ a chuva registrada foi de $467,8 \mathrm{~mm}$, dos quais $53,8 \%$ foram de chuvas frontais e $46,2 \%$ de convectivas. No verão de $2007 / 2008$ o total de chuvas acumulado foi de $406,9 \mathrm{~mm}$, dos quais $56,1 \%$ foram de chuvas frontais e $43,9 \%$ de convectivas. Campo Mourão seguiu a mesma tendência do Sul do Brasil. No ano de La Niña o volume de chuvas foi o menor (tabela 03). As chuvas registradas em Cáceres apresentaram a maior variabilidade entre os anos. No verão $2009 / 2010$ o total foi de $549,3 \mathrm{~mm}$, dos quais $9,9 \%$ foram de chuvas frontais e $90,1 \%$ de convectivas. O verão de 2008/2009 acumulou $418,5 \mathrm{~mm}$, dos quais $2,2 \%$ foram de chuvas frontais e $97,8 \%$ de convectivas. Para o verão de $2007 / 2008$, o volume recebido foi de $885,0 \mathrm{~mm}$, ou seja, no ano de manifestação da La Niña o volume de chuva foi bem superior ao neutro e ao de El Niño. Do total registrado na estação, 3,0\% foram de chuvas frontais e 97,0\% de convectivas. Ferreira et al. (2004) estudaram a composição da Zona de Convergência do Atlântico Sul em períodos de El Niño e La Niña na série histórica de 1980 a 2000 e verificaram que a atividade convectiva, em comparação a anos de EL Niño ou a todos os anos, é mais intensa sobre o continente em anos de La Niña. 
Tabela 03 - Distribuição das chuvas totais e as porcentagens para as frontais e convectivas e as respectivas alturas.

\begin{tabular}{|c|c|c|c|c|c|c|}
\hline Verão & Estação & Chuva & Frontal & Convectiva & Frontal & Convectiva \\
\hline & Campo & & & & & \\
\hline 2009/2010 & Mourão & $587,3 \mathrm{~mm}$ & $36,8 \%$ & $63,2 \%$ & $215,9 \mathrm{~mm}$ & $371,4 \mathrm{~mm}$ \\
\hline 2009/2010 & Cáceres & $549,3 \mathrm{~mm}$ & $9,9 \%$ & $90,1 \%$ & $54,6 \mathrm{~mm}$ & $494,7 \mathrm{~mm}$ \\
\hline 2009/2010 & Caparaó & $407,3 \mathrm{~mm}$ & $39,0 \%$ & $61,0 \%$ & $158,7 \mathrm{~mm}$ & $248,6 \mathrm{~mm}$ \\
\hline $2009 / 2010$ & $\begin{array}{l}\text { Brasília } \\
\text { Campo }\end{array}$ & $472,7 \mathrm{~mm}$ & $8,3 \%$ & $91,7 \%$ & $39,4 \mathrm{~mm}$ & $433,3 \mathrm{~mm}$ \\
\hline $2008 / 209$ & Mourão & $467,9 \mathrm{~mm}$ & $53,8 \%$ & $46,2 \%$ & $251,7 \mathrm{~mm}$ & $216,2 \mathrm{~mm}$ \\
\hline $2008 / 209$ & Cáceres & $418,5 \mathrm{~mm}$ & $2,2 \%$ & $97,8 \%$ & $9,2 \mathrm{~mm}$ & $409,3 \mathrm{~mm}$ \\
\hline $2008 / 209$ & Caparaó & $817,9 \mathrm{~mm}$ & $44,7 \%$ & $55,3 \%$ & $365,6 \mathrm{~mm}$ & $452,3 \mathrm{~mm}$ \\
\hline $2008 / 209$ & $\begin{array}{l}\text { Brasília } \\
\text { Campo }\end{array}$ & $474,4 \mathrm{~mm}$ & $6,6 \%$ & 93,4 & $31,4 \mathrm{~mm}$ & $443,0 \mathrm{~mm}$ \\
\hline $2007 / 2008$ & Mourão & $406,9 \mathrm{~mm}$ & $56,1 \%$ & $43,9 \%$ & $228,4 \mathrm{~mm}$ & $178,5 \mathrm{~mm}$ \\
\hline $2007 / 2008$ & Cáceres & $885,0 \mathrm{~mm}$ & $3,0 \%$ & $97,0 \%$ & $26,6 \mathrm{~mm}$ & $858,4 \mathrm{~mm}$ \\
\hline $2007 / 2008$ & Caparaó & $544,9 \mathrm{~mm}$ & $47,8 \%$ & $52,2 \%$ & $260,2 \mathrm{~mm}$ & $284,7 \mathrm{~mm}$ \\
\hline $2007 / 2008$ & Brasília & $595,5 \mathrm{~mm}$ & $21,3 \%$ & $78,7 \%$ & $127,1 \mathrm{~mm}$ & $468,4 \mathrm{~mm}$ \\
\hline
\end{tabular}

A estação climatológica de Caparaó também registrou irregularidades interanuais. O verão de $2009 / 2010$ recebeu $407,3 \mathrm{~mm}$, dos quais $39,0 \%$ foram de chuvas frontais e $61,0 \%$ de convectivas. Para o verão 2008/2009, ano neutro, ou seja, sem El Niño e sem La Niña, o volume de chuvas foi de $817,9 \mathrm{~mm}, 100 \%$ superior ao recebido no verão $2009 / 2010$, que foi um ano de manifestação do El Niño. Para o verão de 2007/2008 o volume de chuvas registrado em Caparaó foi de $544,9 \mathrm{~mm}$, dos quais $47,8 \%$ foram de chuvas frontais e $52,2 \%$ de convectivas.

A grande participação dos sistemas frontais no tempo em Caparaó $(27,2 \%)$ se justifica ao se considerar que alguns SFs avançam até a latitude de Caparaó, enquanto na fase de frontólise permanecem sobre aquela região por alguns dias. A elevada porcentagem de chuvas classificadas como frontais também se deve a essa observação.

Os SFs que avançam de sudoeste para nordeste raramente atuam em Brasília. Nos três verões considerados a participação apresentou uma grande variabilidade, e a mesma consideração serve para a gênese da chuva. No verão 2009/2010 o volume registrado foi de $472,7 \mathrm{~mm}$, dos quais $8,3 \%$ foram de chuvas frontais e $91,7 \%$ de convectivas. Para o verão de $2008 / 2009$ o volume total registrado foi de $474,4 \mathrm{~mm}$, dos quais $6,6 \%$ foram de chuvas frontais e $93,4 \%$ de conectivas. Para o verão 2007/2008, de manifestação de La Niña, o volume de chuva registrado foi de $595,5 \mathrm{~mm}$, com $21,3 \%$ de chuvas frontais e $78,7 \%$ de chuvas convectivas. 
A tabela 02 mostrou a porcentagem da participação dos SFs no tempo cronológico e nela verifica-se que para as quatro localidades houve aumento na participação dos SFs no verão 2007/2008, ano de manifestação do fenômeno La Niña. Como o estudo se limitou a uma única estação e a apenas três anos, não se pode considerar como tendência. Rao e Hada (1990) concluíram que a correlação entre as chuvas anuais do Sul do Brasil e o Índice de Oscilação Sul (IOS) possui valores negativos e significativos. Segundo Marengo e Oliveira (1998), na Região Centro-Oeste do Brasil não há evidências de efeito pronunciado na precipitação pluvial e na temperatura.

\section{Massa Polar Atlântica}

É um sistema de alta pressão e gerador de estabilidade atmosférica, exceto na zona frontal. No verão sua participação nos tipos de tempo é mais frequente no Sul do Brasil, à medida que ela avança, desvia-se para o interior do Atlântico ao sul, na latitude do trópico de Capricórnio. Por isso, a sua participação decresce para o interior do Centro-Sul do Brasil.

Comparando-se os três verões estudados, verifica-se que durante o evento La Niña a participação se amplia, principalmente para Caparaó. A tabela 04 mostra as porcentagens nos três verões estudados.

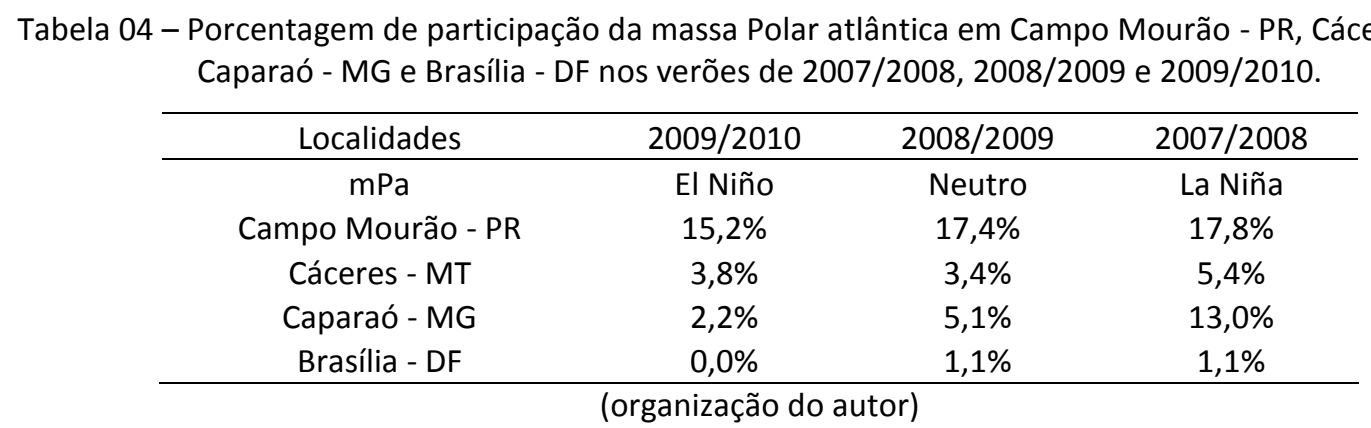

Para Monteiro (1973), após o solstício de verão no hemisfério sul, há um enfraquecimento da $\mathrm{mPa}$, em seus avanço do sul para o norte, atravessa o continente em processo de aquecimento mais intenso, o que implica em que suas propriedades sejam consideravelmente diferentes daquelas observadas no decorrer do inverno. 


\section{Massa Tropical Atlântica}

O centro formador é Alta Subtropical do Atlântico Sul, que se localizam entre as coordenadas $10 \circ$ e $20 \circ \mathrm{W}$ e $20 \circ$ e 40 ㅇ S. Frequentemente cristas avançam para o interior do continente, principalmente a partir do litoral do Nordeste do Brasil, raramente avançando até Cáceres. É um sistema anticiclonal e por isso a umidade se limita à camada de contato com o mar, que fornece vapor. Os ventos dele procedentes, ao tocarem o continente, ascendem para transpor obstáculos oferecidos pelo relevo, condensam-se e podem causar aumento de nebulosidade, neblinas, chuvas orográficas e outros tipos de tempo. Depois dos primeiros obstáculos os ventos avançam pelo interior e a baixa umidade e a estabilidade atmosférica proporcionadas pelo sistema causam dias ensolarados, que, em função do aquecimento diurno, podem causar sistemas convectivos locais com chuvas localizadas.

Em escala local, as condições geográficas da superfície, por meio da variação de altitude da superfície e da forma e orientação das vertentes, geram diferentes tipos de tempo, às vezes distintos daqueles apresentados pelas características básicas da massa de ar.

A tabela 05 mostra a porcentagem da participação da mTa nas quatro estações climatológicas estudadas. Verifica-se que Caparaó, como é a localidade mais próxima do Atlântico e consequentemente do centro de origem do sistema, apresenta a maior porcentagem. Brasília ocupa a segunda posição em participação, seguindo-se Campo Mourão e, por fim, Cáceres, localidade para a qual, nos três verões estudados, em um único dia a mTa avançou por 8 horas. Não se verificam grandes diferenças nos três verões estudados. A mais significativa delas verificou-se para Brasília, que no verão de 2009/2010 teve $15,9 \%$ do tempo cronológico sob a atuação da mTa.

Tabela 05 - Porcentagem de participação da mTa em Campo Mourão - PR, Cáceres - MT, Caparaó - MG e Brasília - DF nos verões de 2007/2008, 2008/2009 e 2009/2010.

\begin{tabular}{cccc}
\hline Localidades & $2009 / 2010$ & $2008 / 2009$ & $2007 / 2008$ \\
\hline mTa & EI Niño & Neutro & La Niña \\
Campo Mourão - PR & $8,2 \%$ & $5,8 \%$ & $6,9 \%$ \\
Cáceres - MT & $0,5 \%$ & $0,0 \%$ & $0,0 \%$ \\
Caparaó - MG & $35,2 \%$ & $32,0 \%$ & $36,4 \%$ \\
Brasília - DF & $15,9 \%$ & $8,4 \%$ & $10,9 \%$ \\
\hline
\end{tabular}

(organização do autor) 


\section{Massa Tropical Continental}

A massa Tropical continental é um sistema de baixa pressão, de origem continental e tem o seu centro de origem na região do Chaco, no Paraguai, em uma zona de alta temperatura e pouca umidade. É uma massa de ar quente e de pouca umidade. No Brasil, atua no CentroOeste e no Oeste das regiões Sul e Sudeste. Com o envelhecimento da $\mathrm{mPa}$ e o seu deslocamento para o interior do Atlântico a mTc se amplia e causa dias ensolarados e de tempo quente e seco.

Campo Mourão é a localidade que mais recebe atuação desse sistema. O maior tempo de atuação em Campo Mourão ocorreu no verão de 2008/2009. A tabela 06 mostra a porcentagem de atuação da mTc nas quatro estações climatológicas estudadas. Caparaó é a localidade de menor atuação, seguida por Brasília.

Tabela 06 - Porcentagem de participação da Massa Tropical Continental em Campo Mourão - PR, Cáceres - MT, Caparaó - MG e Brasília - DF nos verões de 2007/2008, 2008/2009 e 2009/2010.

\begin{tabular}{cccc}
\hline Localidades & $2009 / 2010$ & $2008 / 2009$ & $2007 / 2008$ \\
\hline mTc & El Niño & Neutro & La Niña \\
Campo Mourão - PR & $18,5 \%$ & $24,0 \%$ & $22,3 \%$ \\
Cáceres - MT & $8,2 \%$ & $9,6 \%$ & $4,9 \%$ \\
Caparaó - MG & $5,5 \%$ & $6,2 \%$ & $0,0 \%$ \\
Brasília - DF & $2,7 \%$ & $11,8 \%$ & $0,0 \%$ \\
\hline
\end{tabular}

\section{Massa Equatorial Continental}

A mEc é o sistema mais importante no aspecto umidade, pois a baixa pressão e as elevadas temperatura favorecem a intensificação das correntes convectivas e as precipitações e elevada taxa de umidade. No período do verão as chuvas convectivas acorrem em todo o Centro-Sul do Brasil e são mais abundantes no Centro-Oeste. Como a região é dominada pela atuação desse sistema, as porcentagem mostram (tabela 07) que, para Cáceres e Brasília, a mEc é o sistema com a maior porcentagem de atuação.

Cáceres, no Mato Grosso, avizinha-se com a Amazônia e tem a maior porcentagem de atuação da $\mathrm{mEc}$, sistema de baixa pressão cujo centro de ação se localiza na região central da Amazônia. No Hemisfério Sul, no inverno ela se retrai e atua mais intensamente no Norte do Brasil e nos países daquela região. No verão, ela se amplia e às vezes chega ao Sul do Brasil. 
Tabela 07 - Porcentagem de participação da massa Equatorial continental em Campo Mourão - PR, Cáceres MT, Caparaó - MG e Brasília - DF nos verões de 2007/2008, 2008/2009 e 2009/2010.

\begin{tabular}{cccc}
\hline Localidades & $2009 / 2010$ & $2008 / 2009$ & $2007 / 2008$ \\
\hline mEc & El Niño & Neutro & La Niña \\
Campo Mourão - PR & $42,9 \%$ & $33,7 \%$ & $25,4 \%$ \\
Cáceres - MT & $86,3 \%$ & $83,7 \%$ & $80,4 \%$ \\
Caparaó - MG & $29,7 \%$ & $25,8 \%$ & $13,6 \%$ \\
Brasília - DF & $62,6 \%$ & $65,7 \%$ & $71,2 \%$ \\
\hline
\end{tabular}

(organização do autor)

\section{Zona de Convergência do Atlântico Sul}

A Zona de Convergência do Atlântico Sul (ZCAS) é uma faixa de nebulosidade convectiva que, quando se configura, estende-se desde o Sul da Amazônia em direção ao Sudeste até o Oceano Atlântico Subtropical (QUADRO, 1994). Para Ferreira et al. (2004), a ZCAS é um fenômeno típico do verão na América do Sul e se caracteriza pela persistência de uma banda de nebulosidade no sentido noroeste-sudeste, que atua desde o Centro-Sul da Amazônia em direção ao Oceano Atlântico, de sudoeste.

Ferreira et al. (2004) estudaram a composição da Zona de Convergência do Atlântico Sul em períodos de El Niño e La Niña na série histórica de 1980 a 2000 e verificaram que a atividade convectiva, em comparação a anos de EL Niño ou a todos os anos, é mais intensa sobre o continente em anos de La Niña.

No presente estudo, a participação da ZCAS foi contabilizada a partir da configuração mostrada na carta sinótica da Marinha do Brasil e na observação das imagens de satélite do CPTEC/INPE, canal infravermelho. Não foi verificada a sua intensidade.

Climatologicamente, a ZCAS pode ser identificada, na composição de imagens de satélite, como uma banda de nebulosidade de orientação NW/SE, estendendo-se desde o sul da região amazônica até a região central do Atlântico Sul (ROCHA; GANDÚ, 1996).

Quadro (1994) concluiu que a ocorrência de um caso de ZCAS está relacionada à persistente precipitação nas regiões Sudeste, sul do Nordeste, Norte do Paraná e Brasil Central. As imagens de satélite no canal infravermelho mostraram que a região de Campo Mourão não foi abrangida pela ZCAS no período estudado. A cidade de Campo Mourão ficou ao sul da faixa de nebulosidade que caracteriza a ZCAS.

Os três verões estudados apresentaram a configuração da ZCAS. As análises fundamentadas nas cartas da Marinha do Brasil podem subestimar a participação dela nos tipos de tempo. As convenções que caracterizam a ZCAS só são aplicadas dois ou três dias depois de sua 
configuração. A tabela 08 mostra a participação da ZCAS nas quatro localidades estudadas. Para Cáceres, houve a participação em dois verões, com maior porcentagem para o 2007/2008, ano de manifestação de La Niña. Caparaó e Brasília, por se localizarem na área central do posicionamento preferencial da ZCAS, tiveram porcentagens de participação próximas.

Tabela 08 - Porcentagem de participação da Zona de Convergência do Atlântico Sul em Campo Mourão - PR, Cáceres - MT, Caparaó - MG e Brasília - DF nos verões de 2007/2008, 2008/2009 e 2009/2010.

\begin{tabular}{cccc}
\hline Localidades & $2009 / 2010$ & $2008 / 2009$ & $2007 / 2008$ \\
\hline ZCAS & El Niño & Neutro & La Niña \\
Campo Mourão - PR & $0,0 \%$ & $0,0 \%$ & $0,0 \%$ \\
Cáceres - MT & $0,0 \%$ & $2,0 \%$ & $7,1 \%$ \\
Caparaó - MG & $12,1 \%$ & $11,0 \%$ & $9,8 \%$ \\
Brasília - DF & $13,2 \%$ & $11,0 \%$ & $8,7 \%$ \\
\hline
\end{tabular}

(organização do autor)

O sul das Regiões Sudeste e Centro-Oeste é afetado pela maioria dos sistemas sinóticos que atingem o sul do país, com algumas diferenças em termos de intensidade e sazonalidade do sistema (Quadro et al. 2011). Para ele, a ZCAS é um dos principais fenômenos que influenciam o regime de chuvas dessas regiões.

O estudo da dinâmica dos sistemas atmosféricos para a estação do verão mostra que as massas de ar no Centro-Sul do Brasil no ano de La Niña, no de El Niño e mesmo no neutro, apresentam pouca variação (figuras 03 A, B e C). Apesar da pouca variação, verifica-se que no verão 2007/2008 os SFs apresentaram porcentagens maiores para Cáceres e Brasília.

A dinâmica atmosférica é complexa e envolve também variáveis externas à região - como a circulação geral, o aquecimento das águas oceânicas e as estacionalidades - assim como a geografia da região. Por isso os sistemas atmosféricos apresentam variabilidades interanuais maiores que aquelas verificadas na comparação entre duas ou mais estações do ano. Borsato (2010) estudou a participação dos sistemas atmosféricos na bacia do Alto Rio Paraná no período de 1980 a 2003 e as figuras apresentadas no trabalho mostram quão é grande a variação entre os anos estudados.

Segundo Nimer (1989), o Sudeste e o Centro-Oeste do Brasil, devido às suas localizações latitudinais, caracterizam-se por serem regiões de transição entre os climas quentes de latitudes baixas e os climas mesotérmicos de tipo temperado das latitudes médias. 

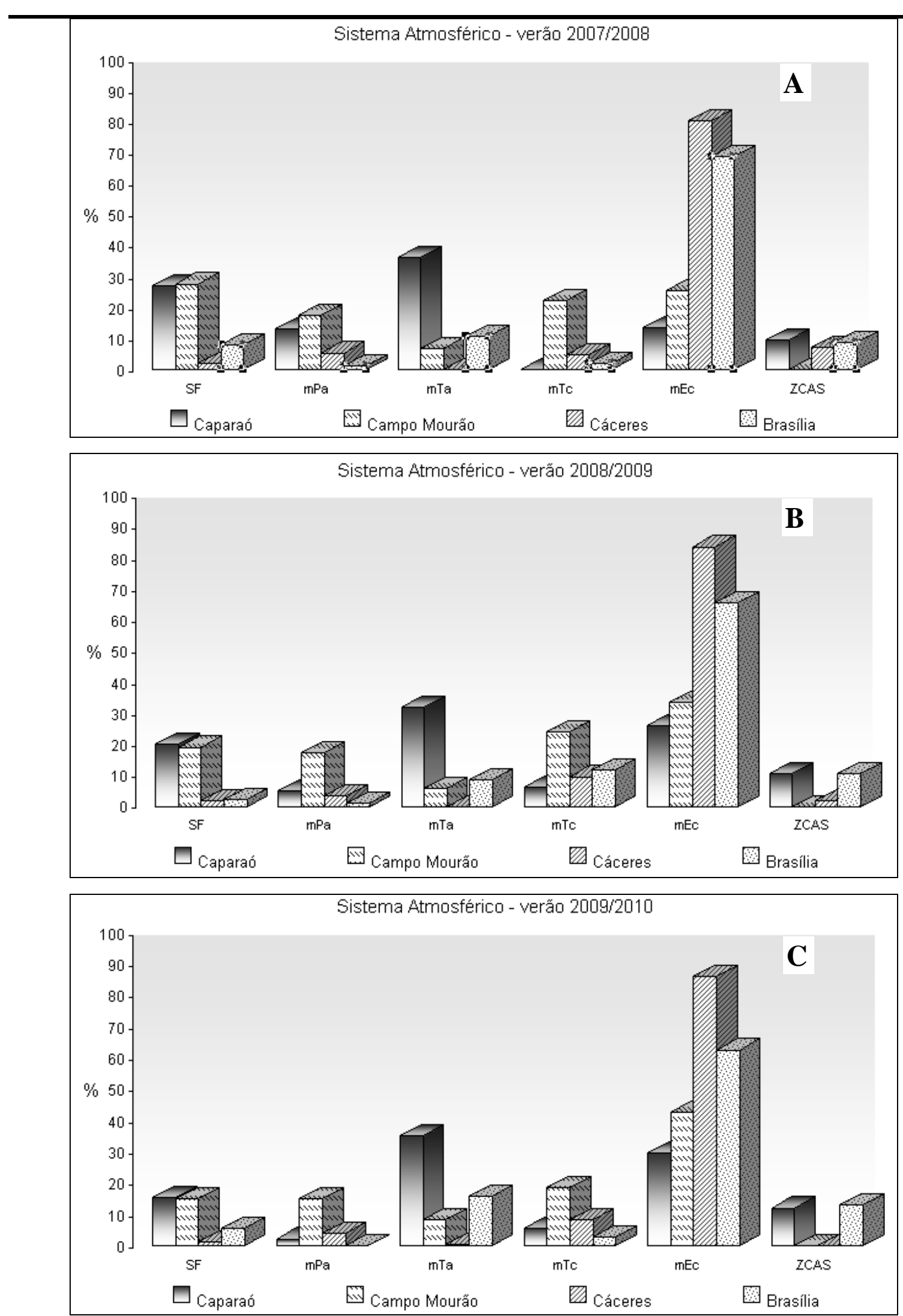

Figuras 03 - Porcentagem da atuação dos sistemas atmosféricos nos verões de 2007/2008 (A) 2008/2009(B) 2009/2010 (C) para Caparaó - MG, Campo Mourão - PR, Cáceres - MT e Brasília.

Organização do autor 


\section{CONSIDERAÇÕES FINAIS}

Os três verões estudados apresentaram variabilidade de uma estação climatológica para as outras, refletindo a espacialização das massas de ar. A localização geográfica da região em relação aos centros de ação justifica a ampla diferença de participação nas quatro estações climatológicas estudadas.

As figuras com as porcentagens de participação dos sistemas foram organizadas com finalidade meramente comparativa, já que não há estudo semelhante para essa região, apesar de despertarem curiosidade e algumas observações, tais como as verificadas para Caparaó, onde o SFs, a mPa, a mEc e a mTc apresentaram um significativo aumento na participação no verão de 2007/2008, enquanto a mTa e ZCAS diminuíram (ano de La Niña). Para Campo Mourão observou-se que para o verão 2007/2008 a mEc teve uma participação menor em comparação aos outro dois verões; por outro lado, a mPa e o SF aumentaram. Brasília apresentou uma participação ligeiramente maior para a mTa e ZCAS no verão 2009/2010. Nessa estação a mEc teve a menor participação, que foi de $62,6 \%$, enquanto no verão 2007/2008 a participação foi de 71,2\%. Em Cáceres prevaleceu a mEc e o verão 2007/2008 foi aquele em que esse sistema apresentou a menor participação: $80,4 \%$.

Em Cáceres e Brasília o tempo de atuação da massa Polar atlântica se limita a eventos esporádicos, enquanto a massa Equatorial continental aumenta na mesma proporção. A principal consequência é o predomínio das chuvas convectivas. Constatou-se também que em Campo Mourão e Caparaó as massas Polar atlântica e Tropical atlântica participaram ativamente nos tipos de tempo.

A dinâmica dos sistemas atmosféricos ao norte da linha do trópico de Capricórnio no CentroSul do Brasil carece de pesquisa mais aprofundada. Para se obterem resultados seguros, o tempo de investigação deverá abranger uma série em que tenham ocorrido pelo menos dois fenômenos El Niño e dois La Niña, e se deverá buscar na estatística uma forma de correlação entre a intensidade e a duração dos sistemas com a altura das chuvas frontais e convectivas.

É evidente que o El Niño e a La Niña causam anomalias tanto nos sistemas atmosféricos que atuam na região como nas chuvas e na temperatura. Para aferi-las ou mensurá-las é necessário, além do estudo de uma série maior, buscar resposta também na intensidade dos sistemas. 


\section{AGRADECIMENTOS}

O autor agradece à Marinha do Brasil pelo fornecimento das Cartas Sinóticas, ao Instituto Nacional de Pesquisas Espaciais, Divisão de Satélites e Sistemas Ambientais pelo fornecimento das imagens de satélite e ao Instituto Nacional de Meteorologia, pelo fornecimento dos dados climatológicos, fundamentais para a execução deste trabalho e ao revisor científico anônimo que em muito contribuiu para a melhoria deste estudo.

\section{REFERÊNCIAS BIBLIOGRÁFICAS}

BERLATO, M.A.; FONTANA, D.C. El Niño e La Niña: impactos no clima, na vegetação e na agricultura do Rio Grande do Sul, aplicações de previsões climáticas na agricultura. Porto Alegre: Ed. da UFRGS, 2003. 110p.

BERLATO, M. A.; FONTANA, D. C. Variabilidade interanual da precipitação pluvial e rendimento da soja no Estado do Rio Grande do Sul. Revista Brasileira de Agrometeorologia, v. 7, p. 119-125. 2000.

BOIN, M. N. - Chuvas e erosões no oeste paulista: uma análise climatológica aplicada. 2000. 264f. Tese (Doutorado em Geociências e Meio Ambiente) - Instituto Geográfico de Ciências Exatas. Universidade Estadual Paulista. São Paulo. 2000.

BORSATO, V. A., A Participação dos sistemas atmosféricos atuantes na bacia do Auto Rio Paraná no período de 1980 a 2003. Tese (parcial), (Doutorado) Nupélia, Universidade Estadual de Maringá. Maringá, 2006.

BORSATO, V. da A. A participação dos sistemas atmosféricos atuantes na bacia do rio Paraná no período 1980 a 2003 . Revista Brasileira de Climatologia. Associação Brasileira de Climatologia. Presidente Prudente. SP. Ano 6 - V.07, pp. 87-102, 2010.

BISCARO, G. A. Meteorologia Agrícola Básica, 10 edição, UNIGRAF - Gráfica e Editora União Ltda. Cassilândia - Mato Grosso do Sul, 2007, 87p. 
BRASIL. Ministério da Marinha. Serviço Meteorológico da Marinha. Cartas sinóticas.

Disponível em <http://www.mar.mil.br/dhn/chm/meteo/prev/cartas/ cartas.htm>, consultado em 26/04/2011

CAPEL MOLINA, J. J., 1999. "El Niño” y el sistema climático terrestre, Barcelona España, editora Ariel, 1999, $154 \mathrm{p}$.

CUNHA, G. R. da. EL NIÑO - Oscilação Sul e perspectivas climáticas aplicadas no manejo de culturas no Sul do Brasil. Revista Brasileira de Agrometeorologia. Santa Maria, v. 7, n. 2. p. 277-284. 1999.

FERREIRA, C.C. Ciclogêneses e ciclones extratropicais na Região Sul-Sudeste do Brasil e suas influências no tempo, INPE-4812-TDL/359, 1989.

FERREIRA, N. J.; SANCHES, M E SILVA DIAS, M. A. F. Composição da Zona de Convergência do Atlântico Sul em Períodos de El Niño e La Niña. Revista Brasileira de Meteorologia, v.19, n.1, $89-98,2004$.

GRIMM, A.M.; GOMES, J. Análise de sensibilidade de método para identificação de anomalias de precipitação relacionadas ao fenômeno El Niño/Oscilação Sul. In: IX Congresso Brasileiro de Meteorologia (9.: 1996: Campos do Jordão), São Paulo: Sociedade Brasileira de Meteorologia, v. 1. p. 742-744, 1996.

INSTITUTO NACIONAL DE PESQUISAS ESPACIAIS. Divisão de Satélite e Sistemas Ambientais (DAS 1995 - 2011. Banco de Dados de Imagens). Imagem no canal infravermelho. Cachoeira Paulista: Acervo Góes, 2011. Imagens MAS Retangulares IR CH 2 do satélite Góes. Disponível em: >http://satelite.cptec.inpe.br/pedidoweb/pedido.formulario.logic<. Acesso em 25 jun. 2011.

INFOCLIMA. Boletim de informações climáticas, CPTEC/INPE. Ano 5. 1998. Disponível em: >http://www.cptec.inpe.br/products/climanalise/infoclima/< consultado em 15/07/2001.

INSTITUTO NACIONAL DE METEOROLOGIA, INMET - Ministério da Agricultura, Pecuária e Abastecimento BDMEP Banco de Dados Meteorológicos para Ensino e pesquisa, disponível em <http://www.inmet.gov.br/projetos/rede/pesquisa/> consultado em 23/01/2011. 
KOUSKY, V. E.; CAVALCANTI, I. F. A. Eventos Oscilação do Sul/El Niño: Características, evolução e anomalias de precipitação, Ciência e Cultura, Vol. 36. n. 11, p. 1888-1899, 1984.

MARENGO, J. A. e OLIVEIRA, G. S. Os impactos do fenômeno La Niña no tempo e no clima do Brasil: desenvolvimento e intensificação da La Niña 1998/99. In: CONGRESSO BRASILEIRO DE METEOROLOGIA, 10, Brasília. Anais. Brasília: SBMET, 1998. 1 CD-ROM.

MONTEIRO, C. A. F. A frente polar atlântica e as chuvas de inverno na fachada sul oriental do Brasil (Contribuição metodológica à análise rítmica dos tipos de tempo no Brasil). São Paulo: IGEOG/USP, n 1, 1969. (Série "Teses e Monografias").

MONTEIRO, A. A. F. A Climatologia do Brasil ante a renovação atual de Geografia: um depoimento. Métodos em Questão. São Paulo, n. 6, 1973

MONTEIRO, C. A. F. O clima e a organização do espaço no estado de São Paulo problemas e perspectivas. São Paulo: IGEOG/USP, n 28, 1976. (Série “Teses e Monografias”).

NERY, J. T.; FERREIRA, J. H. D.; MARTINS, M. L. O. F. 2000. Relação de parâmetros meteorológicos associados a anos de El Niño e La Niña no Estado do Paraná. Apontamentos no 95. Maringá: EDUEM, 64p.

NIMER. E. Climatologia do Brasil. 2.ed. Rio de Janeiro: Instituto Brasileiro de Geografia e Estatística, 1989. 421p.

NOAA, National Oceanic and Atmosféric Administration's. La Niña Information. Disponível em: > http://www.publicaffairs.noaa.gov/lanina.html<, acessado em 20 jun. 2000.

NOAA, National Oceanic and Atmosféric Administration's. National Weather Service, Climate Prediction Equipe Internet Center Centro de Previsão Climática, Última modificação: 05 de julho de 2011, disponível em: >http://www.cpc.ncep.noaa.gov/products/analysis_monitoring/ensostuff/ensoyears.shtmk , acessado em 27 jul. 2011.

PÉDELABORDE, P. Lê climat du bassin parisien: essai d'une méthode rationelle de climatologie physique. Paris: Medicis, 1957. 
QUADRO, M. F. L.; Estudo de Episódios de Zona de Convergência do Atlântico Sul (ZCAS) sobre a América do Sul. 1994. 94f. Dissertação (Mestrado em Meteorologia) - INPE, São José dos Campos.

QUADRO, M. F. L.; MACHADO, L.. H.; CALBETE, S.; BATISTA, N. N. M. e OLIVEIRA, G. S. Climatologia de precipitação e temperatura - Centro de Previsão de Tempo e Estudos $\begin{array}{llllll}\text { Climáticos } & - & \text { CPTEC/INPE } & - & \text { disponível }\end{array}$ >http://climanalise.cptec.inpe.br/ rclimanl/boletim/cliesp10a/chuesp.html< consultado em 10 de setembro de 2011.

RAO,V. B.; HADA, K. Characteristics of Rainfall over Brazil: Annual variation and Connections with the Southern Oscillation, Theoretical Applied Climatology, n.42, p. 81-91, 1990.

ROCHA, A. M. G. C.; GANDU, A. W. A Zona de Convergência do Atlântico Sul. Climanálise, São José dos Campos (SP), v. Esp., p. 140-142, 1996.

ROPELEWSKI, C.F., HALPERT, M.S. Global and regional scale precipitation patterns associated with El Niño - Southern Oscillation, Monthly Weather Rewiev, Boston, v.115, p.1606$1626,1987$.

SCHRODER, R. "Distribuição e Curso Anual das Precipitações no Estado de São Paulo" in: BRAGANTIA - Boletim Técnico do Instituto Agronômico de Campinas. Campinas, v.15, № 18. p. 193-249, 1956.

TARIFA, J.R. Sucessão de tipos de tempo e variação do balanço hídrico no extremo oeste paulista (Ensaio metodológico aplicado ao ano agrícola 1968/69). São Paulo: IGEOG/USP, n 8, 1973. (Série "Teses e Monografias").

VAREJÃO-SILVA M. A., Meteorologia e Climatologia. Instituto Nacional de Meteorologia Brasília, DF, 2000 515p.

VIANELLO, R. L., Meteorologia Básica e Aplicações. Universidade Federal de Viçosa. Editora UFV 2000. 450p.

ZAVATTINI, J. A. A produção brasileira em climatologia: o tempo e o espaço nos estudos do ritmo climático. Terra Livre, São Paulo, AGB Ano 19 - vol. I - n. 20 p. 65 -100. jan/jul. 2003. 
ZAVATTINI, J. A. Estudo do Clima no Brasil, Campinas, SP: Editora Alínea, 2004 398p.

Artigo recebido em 07/09/2011.

Artigo aceito em 05/12/2011. 